\title{
HUBUNGAN ANEMIA PADA IBU HAMIL, HIDRAMNION, DAN KETUBAN PECAH DINI (KPD) TERHADAP KEJADIAN \\ BERAT BAYI LAHIR RENDAH (BBLR) \\ DI RUMAH SAKIT ISLAM SITI KHADIJAH PALEMBANG TAHUN 2018
}

\author{
Jeza Permata Sari, Putu Lusita Nati Indriani \\ Univeritas Kader Bangsa Palembang \\ Fakultas Kebidanan dan Keperawatan Universitas Kader Bangsa Palembang \\ Program Studi DIV Kebidanan Universitas Kader Bangsa Palembang \\ Email: Jezapermatasari@gmail.com
}

\begin{abstract}
ABSTRAK
Latar Belakang: Berat Bayi Lahir Rendah (BBLR) Ialah bayi baru lahir, berat badannya saat kelahiran kurang dari 2.500 gram. Tujuan dari penelitian: Penelitian Ini Bertujuan untuk mengetahui Hubungan anemia, hidramion, KPD terhadap kejadian BBLR di RSI Siti khadijah palembang tahun 2018. Desain penelitian: Penelitian ini menggunakan metode Survey Analitik dengan pendekatan Case Control, populasi dalam penelitian ini adalah semua ibu bersalin dan BBL di RSI siti khadijah Palembang tahun 2018, Penelitian ini dilakukan pada bulan Mei-juni 2019, dengan sampel sebanyak 82. Hasil Penelitian: Hasil penelitian menunjukkan bahwa ibu yang anemia sebanyak $23(28,0 \%)$, ibu yang Hidramnion sebanyak $13(15,9 \%)$, dan ibu yang KPD sebanyak 27 (32,9\%), ibu yang melahirkan bayi dengan BBLR sebanyak 27 (32,9\%), Berdasarkan Hasil analisis Bivariat dengan uji statistic Chi-square menunjukkan bahwa ada hubungan yang bermakna/signifikan antara Anemia dengan BBLR yaitu dengan nilai $\mathrm{p}$-value $=0,002$, berdasarkan analisis bivariat dengan uji statistic Chi-square menunjukkan bahwa tidak ada hubungan yang bermakna/signifikan antara Hidramnion terhadap BBLR dengan nilai $p$-value $0,338<\alpha=0,05$ dan berdasarkan analisis bivariat dengan uji statistic Chi-square menunjukkan bahwa ada hubungan yang bermakna / signifikan antara KPD dengan BBLR dengan nilai p-value $=0,002$. Kesimpulan: Disarankan bagi orang tua untuk dapat memperhatikan kadar $\mathrm{Hb}$, jumlah air ketubann dan keuban pada saat hamil untuk mengurangi kejadian BBLR.
\end{abstract}

Kata Kunci : Anemia, Hidramnion, KPD, BBLR

\section{ABSTRACT}

Background: Low Brith Weight Baby (LBWB) is a newbom whse weigt is less than 2.500 gram atb brith (Maryani, 2013). The purposes of this study: This study armed to find out the relationship of anemia, hydrammnions, PMR, to the meidence of LBWB at Siti Khadijah Islamic Hospital to Palembang in 2018. Research methods This study used the Analytical Survei method with a Cross Sectioal study approach. The population was all mothers giving brith and BBI. Mothers at Siti Khadijah Islamic Hospital to Palembang in 2018. The study was conducted from May to June 2019. The results: With the number of sampel of 82 mothers giving brith the results of the study showed that there were 23 responden $(28,0 \%)$ having anemia and 59 responden (72,0\%) having no anemia. There were 13 responden $(15,9 \%)$ mothers having hydramnions and 69 responden $(84,1 \%)$ having no hydramnions. 
There were 27 responden (32,9\%) having PMR and 55 Responden $(67,1 \%)$ having no KPD. There were 27 responden (32,9\%) gave brith to LBW babies and 55 Responden $(67,1 \%)$ did not. The result of the Bivariat analysis with Chi-square statistical test showed that there was a significant relationship between anemia to LBWB with $p$-value of 0,002 $<\alpha=0,05$. The bivariat analyses with with Chi-square statistical test showed that there was no significant relationship between hydramnions to $L B W B$ with $p$-value of $0,338>\alpha=0,05$ and there was a significant correlation betweeb the PMR and LBWB with p-value of 0,005 $<\alpha=0,05$. Conclusion: It is recommended to pay attenion to Hb levels, the amount of amniotic fluid that seeps to reduce the incedence of $L B W B$.

\section{Keyword : Anemia, Hydramnions, PMR, and LBWB}

\section{PENDAHULUAN}

Bayi BBLR Adalah bayi yang lahir dengan berat badan kurang dari 2.500 gram tanpa memandang masa kehamilannya. Bayi yang berada dibawah persentil 10 dinamakan ringan untuk umur kehamilan. Dahulu neonatus dengana berat badan lahir kurang dari 2.500 grma atau sama dengan 2.500 gram disebut prematur. Pembagian menurut berat badan ini sangat mudah tetapi tidak memuaskan. Sehingga lambat laun diketahui bahwa tingkat morbiditas dan mortalitas pada neonatus tidak hanya bergantung pada berat badan saja, tetapi juga pada tingkat maturitas bayi itu sendiri. (Proverawati, 2010).

Lebih dari 20 juta bayi yaitu sebesar $15,5 \%$ dari seluruh kelahiran mengalami BBLR dan 95\% diantaranya terjadi di negara berkembang, 11,6\% dari total BBLR diseluruh dunia terdapat di Asia Tenggara (WHO,2014). Ini berarti satu dari tuju bayi terlahir dengan BBLR (Kayode et al, 2014).
Bayi Berat Lahir Rendah (BBLR) ialah bayi baru lahir yang berat badannya saat lahir kurang dari 2500 gram. BBLR tidak hanya dapat terjadi pada bayi prematur, tapi juga pada bayi cukup bulan yang mengalami hambatan pertumbuhan selama kehamilan. (Profil Kesehatan indonesia, 2014)

Secara statistik menunjukkan $90 \%$ kejadian BBLR didapatkan di negara berkembang dan angka kematiannya 35 kali lebih tinggi dibanding pada bayi dengan berat lahir lebih dari 2500 gram (WHO, 2007). BBLR termasuk faktor utama dalam peningkatan mortalitas, morbiditas dan disabilitas neonatus, bayi dan anak serta memberikan dampak jangka panjang terhadap kehidupannya dimasa depan (Profil Dinkes Palembang, 2017).

Salah satu indikator untuk mengetahui derajat kesehatan masyarakat adalah Angka Kematian Neonatal (AKN). AKN adalah jumlah bayi yang meninggal satu bulan pertama setelah kelahiran (0-28 
hari) yang dinyatakan dalam 1.000 kelahiran hidup pada tahun yang sama. AKN di Indonesia periode 5 tahun terakhir sejak 2007 mengalami stagnansi. Berdasarkan laporan SDKI (Survei Demografi dan Kesehatan Indonesia) 2007 dan 2012 AKN diestimasikan sebesar 19 per 1.000 kelahiran hidup (Kemenkes RI, 2013). Berdasarkan perkiraan organisasi kesehatan dunia World Health Organization (WHO) hampir semua (98\%) dari lima juta kematian neonatal terjadi di negara berkembang.

Bayi berat lahir rendah (BBLR) adalah bayi dengan berat lahir kurang dari 2500 gram tanpa memandang masa gestasi. Berat lahir adalah berat bayi yang ditimbang dalam 1 (satu) jam setelah lahir. Prevalensi bayi berat lahir rendah (BBLR) diperkirakan 15\% dari seluruh kelahiran di dunia dengan batasan 3,3\%$38 \%$ dan lebih sering terjadi di negaranegara berkembang atau sosio-ekonomi rendah (Profil Dinkes Palembang, 2017).

Berdasarkan data rekam medik di Rumah Sakit Islam Siti Khadijah Palembang tahun 2016 terdapat 42 bayi yang lahir dengan berat $<2500$ gram dari 654 ibu bersalin, pada tahun 2017 terdapat 39 bayi yang lahir dengan berat $<2500$ gram dari 329 ibu bersalin, dan pada tahun 2018 terdapat 32 bayi yang lahir dengan berat $<2500$ gram dari $222 \mathrm{ibu}$ bersalin.

Berdasarkan data diatas maka penulisan tertarik untuk meneliti tentang hubungan anemia pada ibu hamil, hidramnion, Ketuban pecah dini dengan secara simultan dengan kejadian Berat bayi lahir rendah di Rumah sakit islam siti khadijah palembang tahun 2018"

\section{METODE PENELITIAN}

Jenis penelitian ini menggunakan survei analitik dengan menggunakan metode pendekatan Case Control dimana data yang menyangkut variabel bebas atau berisiko dan variabel terikat atau variabel akibat, dikumpulkan dalam watu bersamaan (Sugyono, 2015). Penelitian ini telah dilakukan pada bulan mei-juni 2019 di Rumah Sakit Islam Siti Khadijah Palembang.

Populasi penelitian ini adalah seluruh ibu bersalin yang melahirkan di Rumah Sakit Islam Siti Khadijah Palembang pada tahun 2018.

Sampel penelitian ini adalah sebagian dari jumlah ibu bersalin yang melahirkan BBLR di Rumah Sakit Islam Siti Khadijah berjumlah 82 Responden. Teknik pengambilan sampel dalam penelitian dengan menggunakan cheklist yang berisi nama subjek dan kriteria yang digunakan dalam pengamatan. 
Analisa data yang digunakan adalah analisa data univariat dan analisa bivariat yaitu Analisa yang digunakan untuk melihat distribusi frekuensi dari tiap-tiap variabel, baik variabel Independen (Anemia Pada Ibu Hamil, Hirdramnion, KPD) dan variabel dependen (Berat Badan Lahir Rendah) data di sajikan dalam bentuk teks atau tabel (Notoatmojo,2010).
Teknik pengambilan data menggunakan data sekunder. Data sekunder adalah sumber data yang tidak secara langsung memberikan data kepada pengumpul data (Notoadmojo,2013). Data sekunder penelitian ini didapatkan dari Rekam Medik Rumah Sakit Islam Siti Khodijah Palembang Tahun 2018 dengan menggunakan Cheklist.

\section{HASIL PENELITIAN}

1. Analisa Univariat

\section{Tabel 1}

Analisa Univariat

\section{Distribusi Frekuensi Responden Berdasarkan Kejadian Bayi Berat Badan Lahir} Rendah (BBLR) di RSI Khadijah Palembang tahun 2018

\begin{tabular}{|c|l|c|c|}
\hline No & BBLR & Frekuensi (N) & Persentase \% \\
\hline 1 & BBLR & 27 & $32,9 \%$ \\
\hline 2 & Tidak BBLR & 55 & $67,1 \%$ \\
\hline No & Anemia & Frekuensi (N) & Persentase \% \\
\hline 1 & Anemia & 23 & $28,0 \%$ \\
\hline 2 & Tidak Anemia & 59 & $72,0 \%$ \\
\hline No & Hidramnion & Frekuensi (N) & Persentase \% \\
\hline 1 & Ya & 13 & $15,9 \%$ \\
\hline 2 & Tidak & 69 & $84,1 \%$ \\
\hline No & KPD & Frekuensi (N) & Persentase \% \\
\hline 1 & Ya & 27 & $32,9 \%$ \\
\hline 2 & Tidak & 55 & $67,1 \%$ \\
\hline \multicolumn{2}{r|}{ Jumlah } & $\mathbf{8 2}$ & $\mathbf{1 0 0 \%}$ \\
\hline
\end{tabular}

Berdasarkan tabel diatas bahwa dari 8 responden yang diteliti, proporsi ibu yang mengalami hidramnion adalah sebanyak 13 responden (15,9\%), lebih sedikit dibandingkan dengan ibu yang tidak mengalami hidranion yaitu sebanyak 69 responden $(84,1 \%)$.
Berdasarkan tabel diatas bahwa dari 82 responden yang diteliti, proporsi ibu yang mengalami Ketuban pecah dini (KPD) adalah sebanyak 27 responden (32,9\%), lebih sedikit dibandingkan dengan ibu yang tidak mengalami Ketuban pecah dini (KPD) yaitu sebanyak 55 responden $(67,1 \%)$. 
Tabel 2

Analisa Bivariat

Distribusi Frekuensi Responeden Berdasarkan Anemia, Hidramnion, dan Ketuban Pecah Dini (KPD) pada Ibu Hamil di RSI Siti Khadijah Palembang tahun 2018

\begin{tabular}{|c|c|c|c|c|c|c|c|c|c|}
\hline \multirow{3}{*}{ No } & \multirow{3}{*}{ Variabel } & \multicolumn{4}{|c|}{ Bayi BBLR } & \multirow{2}{*}{\multicolumn{2}{|c|}{ Jumlah }} & \multirow{3}{*}{ p_value } & \multirow{3}{*}{ OR } \\
\hline & & \multicolumn{2}{|c|}{ BBLR } & \multicolumn{2}{|c|}{$\begin{array}{l}\text { Tidak } \\
\text { BBLR }\end{array}$} & & & & \\
\hline & & $\mathrm{n}$ & $\%$ & $\mathrm{~N}$ & $\%$ & $\mathrm{~N}$ & $\%$ & & \\
\hline 1 & $\begin{array}{l}\text { Anemia } \\
\text { a. Anemia } \\
\text { b. Tidak Anemia }\end{array}$ & $\begin{array}{l}14 \\
13\end{array}$ & $\begin{array}{l}60,9 \\
22,0\end{array}$ & $\begin{array}{c}9 \\
46\end{array}$ & $\begin{array}{l}39,1 \\
78,0\end{array}$ & $\begin{array}{l}23 \\
59\end{array}$ & $\begin{array}{l}100 \\
100\end{array}$ & 0,002 & $\begin{array}{c}5,504 \\
1,947-15,562\end{array}$ \\
\hline 2 & $\begin{array}{l}\text { Hidramnion } \\
\text { a. Ya } \\
\text { b. Tidak }\end{array}$ & $\begin{array}{c}6 \\
21\end{array}$ & $\begin{array}{l}46,2 \\
30,4\end{array}$ & $\begin{array}{c}7 \\
48\end{array}$ & $\begin{array}{l}53,8 \\
69,6\end{array}$ & $\begin{array}{l}13 \\
69\end{array}$ & $\begin{array}{l}100 \\
100\end{array}$ & 0,338 & $\begin{array}{c}1,959 \\
0,587-6,537\end{array}$ \\
\hline 3 & $\begin{array}{l}\text { Ketuban Pecah Dini } \\
\text { a. Ya } \\
\text { b. Tidak }\end{array}$ & $\begin{array}{l}15 \\
12\end{array}$ & $\begin{array}{l}55,6 \\
21,8\end{array}$ & $\begin{array}{l}12 \\
43\end{array}$ & $\begin{array}{l}44,4 \\
78,2\end{array}$ & $\begin{array}{l}27 \\
55\end{array}$ & $\begin{array}{l}100 \\
100\end{array}$ & 0,005 & $\begin{array}{c}4,4791,160- \\
12,088\end{array}$ \\
\hline
\end{tabular}

Berdasarkan tabel 2 dapat dilihat bahwa anemia dan Keuban pecah dini (KPD) secara statistik berhubungan dengan Berat bayi lahir rendah (BBLR). Sedangkan Hidramnion tidak berhubungan secara statistik dengan kejadian Berat bayi lahir rendah (BBLR). Anemia merupakan variabel yang paling dominan berhubungan dengan BBLR.

\section{PEMBAHASAN}

Penelitian ini sejalan dengan penelitian Hidayati (2016), Terlihat ada hubungan antara kadar $\mathrm{Hb}$ pada saat melahirkan dengan BBLR. berdasarkan uji statistik didapatkan nilai p_value sebesar 0,01 yang berati terdapat hubungan yang bermakna antara kadar $\mathrm{Hb}$ saat melahirkan dengan kejadian BBLR. Hasil analisis didapatkan nilai OR sebesar 2,39 (95\% CI : 1,18-4,84) yang memiliki arti bahwa ibu yang melahirkan dengan anemia memiliki risiko 2,39 kali lebih tinggi untuk melahirkan bayi BBLR dibandingkan dengan ibu bersalin yang tidak menderita anemia.

Hasil penelitian ini sejalan dengan teori bahwa defisiensi anemia yang dialami ibu hamil lebih berpengaru terutama dapat berdampak pada janin yang sedang berkembang seperti berkurangnya sel darah merah (eritrosit) dalam sirkulasi darah atau massa hemoglobin sehingga tidak mampu memenuhi fungsinya sebagai pembawa oksigen keseluru jaringan (Tarwoto, 2016). Anemia dalam kehamilan didefinisikan sebagai penurunan kadar hemoglobin kurang dari $11 \mathrm{~g} / \mathrm{dl}$ selama masa kehamilan pada trimester I dan III dan kurang dari $10 \mathrm{~g} / \mathrm{dl}$ selama masa post partum dan trimester II (Proverawati, 
2009). Wanita hamil paling rentang terkena anemia, ketika seorang hamil volume darah dalam tubuh akan meningkat sekitar 50\% karena tubuh memerlukan tambahan darah yang berguna mensuplai oksigen dan makanan untuk pertumbuhan janin (Pudiastuti, 2011).

Penelitian ini tidak sejalan dengan penelitian sukma (2015), tentang hidramnion, pengaruh berat badan lahir bayi dengan hidramnion pada bayi baru lahir. Hasil penelitian ada hubungan antara berat badan lahir dengan kejadian hidramnion pada balita usia 06-36 bulanbayi baru lahir dengan nilai $p=0.02$ (< 0.05). Ada hubungan antara berat badan lahir bayi dengan hidramnion pada pada bayi baru lahir dengan nilai $p=0.02$ $(<0.05)$.

Penelitian ini sejalan dengan penelitian Aditya (2016), Berdasarkan pengumpulan data dan analisis, terdapat hubungan antara BBLR dengan nilai $p=0,009 \quad(p<0,05)$. Hal ini menunjukan bahwa terdapat hubungan antara BBLR (Bayi berat lahir rendah) dengan KPD (Ketuban Pecah Dini) $(\mathrm{p}<0,05)$. pada penelitian ini menunjukan koefisiensi korelasi sebesar 0,146.

Hasil penelitian ini sejalan dengan teori bahwa defisiensi Kematangan janin dapat diobservasi melalui perawatan antenatal, siklus menstruasi dan ultrasonografi. Analisis fosfolipid vagina membantu untuk menentukan maturitas paru-paru janin. Pada kehamilan yang belum mencapai aterem adalah penting untuk mempertimbangkan resiko yang ditemui jika dilakukan persalinan dibandingkan dengan resiko infeksi yang timbul jika persalinan dibiarkan berlanjut. Pemberian kortikosteroid dapat menghindari sindrom gawat pernapasan jika persalinan menjadi diperlukan. Kehamilan yang belum aterem yang tidak mengalami komplikasi dapat dipertibangkan untuk dilanjutkan jika pengawasan dapat dilakukan. (Lilis, 2012).

\section{KESIMPULAN}

Variabel Anemia dan Ketuban pecah dini merupakan faktor risiko terhadap kejadian Berat Bayi Lahir Rendah

\section{DAFTAR PUSTAKA}

1. Arikunto, Suharsimi. 2013. Prosedur Penelitian Suatu pendekatan praktik. Jakarta : PT Rineka Cipta

2. Dewi, dkk. 2011. ASUHAN KEHAMILAN untuk KEBIDANAN. Jakarta : Salemba Medika

3. Dewi, Vivian nanny lia. 2010. ASUHAN NEONATUS BAYI DAN 
ANAK BALITA. Jakarta : Salemba Medika

4. Fadlun, dkk. 2012. ASUHAN KEBIDANAN PATOLOGI. Jakarta : Salemba Medika

5. Indiarti, M.T. 2015. Panduan Terbaik A-Z Kehamilan Persalinan dan Perawatan Bayi. Yogyakarta. Indoliterasi

6. Jaya, N. 2009. Analisis Faktor Risiko Kejadian BBLR di Rumah Sakit Ibu dan Anak Siti Fatimah Makasar. Media Gizi Pangan. Vol. VII Edisi 1: 49-54

7. Jitowiyono, S dkk. 2011. Asuhan Keperawatan Neonatus dan Anak. Yogyakarta : Nuha Medika

8. Joshi. H.,S dkk, 2014. Risk Factor for Law Brith (LBW) Nanies and its Medico-Lefal Significance. J Indian Acad Med.

9. Lisnawati, Lilis. 2012. ASUHAN KEBIDANAN dan Kegawatdaruratan Maternal \& Neonatal. Jakarta : CV TRANS INFO MEDIA

10. Maryunani, Anik. 2014. ASUHAN NEONATUS, BAYI, BALITA \& ANAK PRA-SEKOLAH. DKI Jakarta : CV TRANS INFO MEDIA.

11. Maryunani, Anik. 2013. Buku saku Asuhan Bayi dengan Berat Badan Lahir Rendah. DKI Jakarta : CV TRANS INFO MEDIA.
12. Notoatmojo,S. 2012. Metodelogi Penelitian. Jakarta: Badan Penerbit Kesehatan Masyarakat Fakultas Kedokteran Universitas Indonesia

13. Nugroho, Taufal. 2015. Patologi Kebidanan. Yogyakarta: Nuha Medika 14. Pudiastuti, R,D. 2011. Buku Ajar Kebisanan Komunitas.Yogyakarta: Nuha Medika

15. Proverawati, Atika 2011. Anemia dan Anemia Kehamilan. Yogyakarta: Nuha Medika

16. Proverawati, dkk. 2010. BBLR Berat Badan Lahir Rendah. Yogyakarta: Nuha Medika

17. Proverawati, dkk. 2009. Buku Ajar Gizi Untuk Kebidanan. Yogyakarta: Nuha Medika

18. Rukiyah, dkk. 2010. Asuhan Kebidanan 4 (Patologi). Jakarta : TIM

19. Saputra, Lyndon. 2014. Pengantar Asuhan Neonatus Bayi dan Anak Balita. Tangerang Selatan : BINA RUPA AKSARI PUBISHUNG

20. Sugiyono, 2015, Metode Penelitian Pendidikan,Pendekatan Kuantitatif Kualitatif dan R\&D. Bandung : Alfabeta.

21. Sujarweni, V.wiratna. 2015. Statistik Untuk Kesehatan. Yogyakarta : GAVA MEDIA

22. Sukarni, dkk. 2014. PATOLOGI Kehamilan, Persalinan, Nifas, dan 
Neonatal Risiko Tinggi. Yogyakarta :

Nuha Medika.

23. Tarwoto, dkk. 2016. Buku Saku Anemia Pada Ibu Hamil, Konsep dan Penatalaksanaanya. Jakarta : TIM.

24. Aditya, Nara Dikna. 2016. Hubungan Bayi Berat Badan Lahir Rendah dengan Ketuban Pecah Dini. Surabaya

25. Andria, 2017. Hubungan Anemia Pada Ibu Hamil dengan Kejadian Berat Badan Lahir Rendah (BBLR) di RSUD Rokan Hulu. Riau. diakses April 2019

26. DEPKES RI, 2017. Profil Kesehatan Palembang 2017, diakses April 2019.

27. DEPKES RI, 2015. Profil Kesehatan Sumsel 2015. diakses April 2019

28. Hidayati, Isti. 2016. Faktor-faktor yang mempengaruhi kejadian Bayi Berat Lahir Rendah (BBLR) di RSUD Prambanan. Yogyakarta. diakses April 2019.
29. Liesmayani, Elvi Era. 2014. Hubungan Anemia Ibu hamil dengan Kejadian Bayi Berat Badan Lahir Rendah (BBLR)di RSU Kabanjahe. Medan. diakses April 2019

30. Ningsih, Nursamsita. 2016. Hubungan Berat Badan Lahir Rendah (BBLR) Ketuban Pecah Dini (KPD) dan Persalinan Prematur dengan Kejadian Sepsis Neonatus di badan layanan umum daerah RS Benyamin. Kendari. diakses April 2019

31. Sulistyorini, dkk. 2015. Analisis Faktor-faktor yang Mempengaruhi kejadian BBLR di Puskes Perkotaan. Banjarnegara. diakses April 2019

32. Yuniatini, Ummy. 2016. Hubungan Antara Usia dan Jarak Kehamilan Sebelumnya dengan Berat Bayi Lahir Rendah di RS gunung Kidul. Yogyakarta. diakses April 2019 